\title{
Do Pediatric Anesthesiologists Need to Stop Using General Anesthetics?
} \author{
Adnan ${ }^{13}$ and Arham Mubarakali Hirani ${ }^{14}$ \\ ${ }^{1}$ National University of Sciences of Technology, Pakistan \\ ${ }^{2}$ Fatima Jinnah Medical College, Pakistan \\ ${ }^{3}$ Thomas Jefferson University, USA \\ ${ }^{4}$ King Edward Medical University, Pakistan \\ ${ }^{5}$ NYU Langone Health New York, USA \\ ${ }^{6}$ Damascus Hospital, Syria \\ ${ }^{7}$ Dow University of Health Sciences, Pakistan \\ ${ }^{8}$ Eastern Virginia Medical School, USA \\ ${ }^{9}$ Ayub Medical College, Khyber Medical University, Pakistan \\ ${ }^{10}$ Northwestern Medicine Hospital, USA \\ ${ }^{11}$ Nishtar Medical University, Pakistan \\ ${ }^{12}$ University of health sciences, Pakistan \\ ${ }^{13}$ Centre for Addiction and Mental Health, Canada \\ ${ }^{14}$ Zia Uddin National University, Pakistan
}

Masood Quratulain Fatima1*, TAIMIA AYUB ${ }^{2}$, Sara Habib ${ }^{3}$, Abdullah Sohail ${ }^{4}$, AsimHaider ${ }^{4}$, Zunaira Mahmood ${ }^{5}$, Mudasar Hassan ${ }^{5}$, Munther AlShalabi ${ }^{6}$, Fnu Sandeep ${ }^{7}$, Maira Shahid ${ }^{7}$, Talha Perwez ${ }^{7}$, Sheikh Bilal Khalid ${ }^{8}$, Muhammad Waqas ${ }^{9}$, Atif Ibrahim ${ }^{9}$, Faiza Siddiqui ${ }^{10}$, Jawaria Rasheed ${ }^{11}$, Zainab Khan ${ }^{11}$, Umer Zia ${ }^{12}$, Mahwish

Submission: September 25, 2017; Published: November 27, 2017

*Corresponding author: Masood Quratulain Fatima, National University of Sciences of Technology, Pakistan, Email: quratulain.fatima@gmail.com

Abbreviations: PANDA: Pediatric Anesthesia Neuro Development Assessment; GAS: General Anesthesia vs. Spinal anesthesia; MASK: Mayo Anesthesia Safety in Kids; NMDA: N-methyl-D-Aspartate Receptor; GABA: Gamma-Amino Butyric acid

\section{Introduction}

FDA issued a cautionary declaration in December 2016, stating that repetitive and prolonged use of sedative and general anesthetics risks pediatric neurological injury. Sedatives and general anesthetics, used in the third trimester and in the pediatric population younger than three years of age, were particularly lectured in the mentioned testimony. Could careless use of anesthetics in pediatric patients affect neurodevelopment of children? Literature fails to confirm abnormalities in behavior, learning and memory. This is a vital question, with far reaching implications at pediatrics, anesthesia, and surgery.

General anesthetics affect NMDA and GABA receptors. They have revealed extensive apoptotic and neurodegenerative deviations in developing animal brains. Such abnormalities are worsened on repeated anesthetic intervention. Pediatric neurologic injury may include a spectrum of clinical abnormalities including learning disabilities, memory loss and cognition defects. Trials included general anesthesia exposure in a wide variety of animals ranging from rodents to non-human primates. Nevertheless the results in human studies are far from being conclusive.

Studies like PANDA, Pediatric Anesthesia Neuro Development Assessment, have shown that a single short time exposure to an aesthesia in young children results in no noteworthy neurodevelopment abnormalities.

Similarly GAS (General Anesthesia vs Spinal anesthesia) study is a randomized controlled trial, which aims to investigate the 
long-term effects of spinal and general sevoflurane anesthesia in new-borns. It tests for developmental outcomes at 2 years of age and then neuro developmental and intelligence outcomes at 5 years of age. The trial reveals results that state that less than one hour of sevoflurane, in infancy increases the risk of adverse neuro developmental outcome at 2 years of age; compared with awakeregional anesthesia. There is still a need to study long term effects during late childhood, teenage and adulthood. Spinal anesthesia has been described as a relatively safer, alternate to general anesthesia in younger children where applicable for example in operations like herniorrhaphy.

In another study, a single general anesthesia exposure before thirty-six months of age in healthy children was associated with a neurocognitive outcome statistically similar IQ levels, compared to healthy siblings. Mayo Anesthesia Safety in Kids (MASK) Study is an undergoing population-based cohort study of long-term cognitive development in children with no anesthetic exposure to those with single or multiple exposures before 3 years of age. The prospective study promises an intriguing insight comparing long term or multiple episodes of early anesthesia exposure. Supplementary studies suggest that children with multiple exposures are more likely to develop adverse outcomes resulting in ADHD, learning and attention issues. There has been an ongoing debate that FDA safety update regarding general anesthesia and sedation in young children and pregnant females may lead to delay in essential surgical procedures which might result in nonfavorable results.

\section{Conclusion}

In short, while there is definite evidence of unfavorable neurological outcome of general anesthesia exposure in young animals, there is still need for further trials and studies to prove so in humans. This should be explored so at inter disciplinary manner by involving larger sample sizes and studying effects over longer periods of time. At the same time, better options than general anesthetics must be investigated, with more emphasis on local anesthetics to be used in the pediatric population.

\section{References}

1. FDA Drug Safety Communication: FDA review results in new warnings about using general anesthetics and sedation drugs in young children and pregnant women, USFDA.

2. Ikonomidou C, Bosch F, Miksa M, Bittigau P, Vöckler J (1999) Blockade of NMDA receptors and apoptotic neurodegeneration in the developing brain. Science 283(5398): 70-74

3. Paule MG, Li M, Allen RR, Liu F, Zou X (2011) Ketamine Anesthesia during the First Week of Life can Cause Long-Lasting Cognitive Deficits in Rhesus Monkeys. Neurotoxicol Teratol 33(2): 220-230.

4. San Francisco (2016) Study of a Single, Short Exposure to General Anesthesia in Young Children Encouraging, Says Pediatric Group. Smart Tots p. 1-3.

5. Jones LJ, Craven PD, Lakkundi A, Foster JP, Badawi N (2015) Regional (spinal, epidural, caudal) versus general anaesthesia in preterm infants undergoing inguinal herniorrhaphy in early infancy. Cochrane Database Syst Rev 9(6): CD003669.

6. Lena S Sun, Li G, Miller TL, Salorio C, Byrne M, et al (2016) Association Between a Single General Anesthesia Exposure Before Age 36 Months and Neurocognitive Outcomes in Later Childhood JAMA 315(21): $2312-2320$

7. Dean B Andropoulos, Michael F Greene (2017) Anesthesia and Developing Brains-Implications of the FDA Warning. N Engl J Med 376 905-907.

Your next submission with Juniper Publishers will reach you the below assets

Commons Attribution 4.0 License

DOI: 10.19080/JAICM.2017.04.555638 